\title{
Entre arquivos e memórias: o acervo do Colégio Municipal Pelotense e a inserção de professoras secundaristas
}

\section{Bruna de Farias Xavier}

Universidade Federal de Pelotas (UFPel)

\section{Patrícia Weiduschadt}

Universidade Federal de Pelotas (UFPel)

\section{Resumo}

O presente artigo tem o propósito de apresentar os bastidores de uma pesquisa historiográfica que vem sendo desenvolvida no acervo escolar do Colégio Municipal Pelotense, localizado na cidade de Pelotas (RS). Tal pesquisa tem como tema central o processo de inserção da mulher no magistério do ensino secundário do referido colégio, no período compreendido entre as décadas de 1940-1950, a partir da análise de documentos escolares, como fichas funcionais de seis professoras admitidas durante este período. Até o momento, podemos concluir que mesmo com todo o debate da época e o discurso de inserção da mulher no ensino primário, as relações de gênero envolvịdas no ensino secundário no período ainda privilegiavam a classe masculina, ao menos nesta instituição.

Palavras-chave: História da Educação; Documentos escolares; Colégio Municipal Pelotense; Feminização do magistério.

\section{Among files and memories: the collection of Pelotense Municipal School and the insertion of female secondary teachers}

\section{Abstract}

This article has the purpose to present the backstage of a historical research that has been developed in the school collection of the Pelotense Municipal School, located in the city of Pelotas (RS). This research is focus on the women's insertion process in teaching at secondary education in the period between 1940-1950, specially from school documents analysis as functional records of six teachers admitted during this period. So far we can conclude that even with all the debate and the woman insertion in primary education speech, gender relations involved in secondary education period still favored the male class, at least in this institution.

Keywords: History of education; School documents; Pelotense City School; Feminization of the magisterium. 


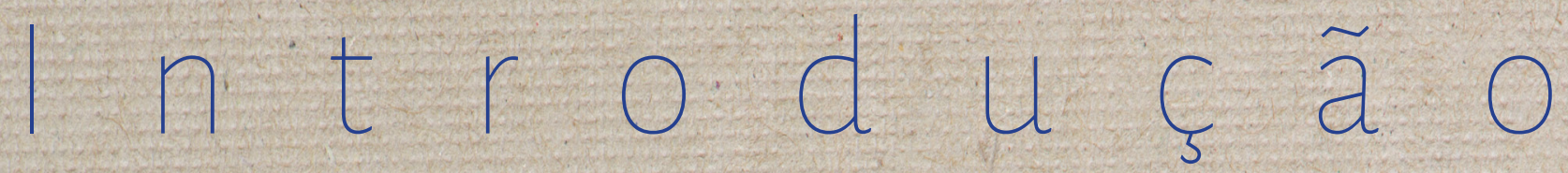

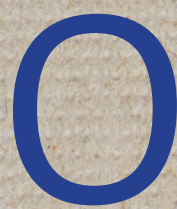
presente artigo está relacionado ao campo da História da Educação e tem por objetivo apresentar os bastidores de uma pesquisa que vem sendo realizado no acervo do Colégio Municipal Pelotense, localizado na cidade de Pelotas (RS), Brasil.

Saliento aqui a riqueza de histórias presente neste ambiente de documentos escolares diversos e as mais variadas possibilidades de pesquisa contidas em um acervo deste nível, as quais muitas vezes passam despercebidas. Pretendemos, ainda, discutir o tema escolhido para a pesquisa de mestrado, fruto do trabalho colaborativo no acervo documental do Colégio Municipal Pelotense e da observação cuidadosa de determinados documentos nele existentes.

Ao longo deste processo, surgiram indagações que originaram uma pes- quisa historiográfica, que trata do estudo de registros escritos da história, tendo por base o sentido de que a historiografia é a arte de escrever e registrar os eventos do passado. Conforme Certeau (2000, p. 66) a "pesquisa historiográfica se articula com um lugar de produção sócio-econômico, político e cultural. [...] Ela está, pois, submetida a imposições, ligada a privilégios, enraizada em uma particularidade".

Nesta acepção, o estudo historiográfico deve ser contextualizado num sentido geral e se fixa no micro, o Colégio Municipal Pelotense, com todas suas especificidades, para compreender o macro, ou seja, as relações quanto à feminização do magistério, que possivelmente tenham ocorrido também em outras instituiçốes de ensino em um cenário mais amplo.

A pesquisa e indagações abordadas se dão através da análise de diversos do- 
cumentos escolares encontrados no acervo documental deste estabelecimento. Como colocam Samara e Tupy (2010, p. 68), as pesquisas históricas, estariam calcadas num conjunto "de registros, de um ou mais tipos, constituindo uma amostra cuja amplitude varia em função dos vários requisitos da análise: a abrangência do tema, a quantidade disponível de informações, o estado da documentação, o período de referência, entre tantos outros".

De acordo com Amaral (2005), o Colégio Municipal Pelotense, foi fundado em 24 de outubro de 1902 pela Loja Maçônica Antunes Ribas' ${ }^{7}$ com o nome de Cymnasio Pelotense, voltado ao ensino secundário de caráter laico, por não possuir qualquer vínculo com a igreja e misto, pois abrangeria um ensino no qual meninos e meninas estudariam juntos, uma vez que em determinadas escolas da região as turmas eram separadas também por gênero. A ideia de fundação do colégio surge a fim de fazer forte oposição a outro estabelecimento de ensino local de grande prestígio na época, o Colégio Gonzaga², fundado

1 Loja é o nome designado ao local reservado às reuniões da Ordem Maçônica.

2 De acordo com Amaral (2005, p. 17), o Colégio Conzaga foi criado em 1894 , sendo o primeiro colégio religioso de ensino secundário, fundado pelos jesuítas, na cidade de Pelotas segundo os princípios da Igreja Católica. O Cinásio Pelotense foi municipalizado na década de 1920 , recebendo a denominação atual em 1943, quando passou a ser reconhecido como Colégio Municipal Pelotense.

A escolha deste estabelecimento de ensino para a realização da pesquisa decorre do fato desse ser o maior e um dos mais importantes colégios da época na região, chegando a ser equiparado ao Colégio Pedro $\|^{3}$, como comprovam documentos encontrados no acervo da escola, que datam de agosto de 1929 e enfatizam seu discurso a favor de um ensino laico e misto, divergindo das demais instituições de ensino local.

\section{O acervo escolar do Colégio Municipal Pelotense e a feminização do magistério}

No caso do Colégio Municipal Pelotense, a importância de seu acervo está não só em se tratar de um estabe-

3 Instituição criada pelo Governo Imperial, em 1837, para servir de modelo em relação ao ensino secundário, visando à uniformização do ensino nas demais escolas públicas e privadas (VECHIA, 2010). 
lecimento de ensino e, assim, colaborar com a preservação de documentos que revelam a história, os bastidores e as práticas escolares ocorridas neste ambiente, mas também por representar uma instituição centenária na cidade, fundada em meio a embates ideológicos marcantes no contexto local da época.

Neste trabalho, compreendemos os documentos escolares analisados assim como Nunes (2011, p. 22), que os considera

uma escrita carregada de significados ideológicos, passível de sobreposição de valores éticos e relativos ao posicionamento crítico do pesquisador, a fim de reconstruir uma narrativa de verossimiIhança com uma versão o mais aproximada do real acontecido, é que nos colocamos diante dos materiais selecionados para a confecção da pesquisa.

Sendo assim, pretendemos a presentar alguns indícios do processo de feminização ${ }^{4}$ do magistério no ensino secundário do Colégio Municipal Pelotense, bem como quem foram as primeiras professoras admitidas para lecionar,

4 Para o conceito de feminização, adotaremos o mesmo utilizado por Yannoulas (2011), que trata a respeito de quando uma profissão passa a ser desempenhada por mulheres, estabelecendo mudanças em sua representação, o que será aprofundado no texto. o período no qual estas passam a ser admitidas, sua formação e as possíveis relações de gênero existentes na épo-, ca, instituídas nas práticas escolares deste estabelecimento.

Neste estudo, temos que a escola também porta características que são absorvidas enquanto reflexo da cultura social, isto é, em relação ao contexto e tempo em que está inserida.

Além disso, partimos do pressuposto de que, na pesquisa em História da Educação, analisar somente a legislação ou a história do contexto social local não satisfaz as respostas de certas perguntas relacionadas às práticas organizacionais efetivadas pelas escolas. Para esse tipo de pesquisa e para entender as peculiaridades de cada instituição, nada como a análise dos arquivos escolares, pois por mais que estes não expressem de forma clara como se davam as relações escolares, nos possibilitam levantar possíveis hipóteses sobre estas relações, quando cruzados com o contexto local da época e as legislações vigentes.

Neste sentido, todo documento encontrado deve ser averiguado em suas 
mais variadas possibilidades de representaçãos, a fim de que possa revelar uma significação dentro do recorte analítico pretendido.

No caso desta pesquisa, corroborando com Pesavento (2004, p. 41),

as representações são também portadoras do simbólico, ou seja, dizem mais do que aquilo que mostram ou enunciam, carregam sentidos ocultos, que, construídos social e historicamente, se internalizam no inconsciente coletivo e se apresentam como naturais, dispensando reflexão.

Aqui, as representações permitem refletir sobre o processo de inserção da mulher no ensino secundário enquanto professora, analisando os aspectos que colaboraram para o desenvolvimento deste cenário de inserção no Colégio Municipal Pelotense, o que demanda um alargamento de fontes. Nesse sentido, todos os documentos encontrados passam pelo crivo do olhar da pesquisadora e, assim, a relação entre pesquisador e documento se estabelece num campo de proximidade e não de veracidade, pois não se tem a pretensão de que os documen-

5 Nesta pesquisa utiliza-se o conceito de representação segundo Pesavento (2004, p. 40), onde "[a] representação não é uma cópia do real, sua imagem perfeita, espécie de refleXo, mas uma construção feita a partir dele" tos sejam a verdade, e sim que representem, através dos vestígios e pistas neles contidos, como possivelmente, essas relações de gênero eram estabelecidas neste colégio, bem como pronuncia Pesavento (2004, p. 24):

na reconfiguração de um tempo - nem passado nem presente, mas tempo histórico reconstruído pela narrativa - face à impossibilidade de repetir a experiência do vivido, os historiadores elaboram versões. Versões plausíveis, possíveis, aproximadas, daquilo que teria se passado um dia. O historiador atinge, pois, a verossimilhança, não a veracidade. Ora, o verossímil não é a verdade, mas algo que com ela se aparenta: O verossímil é o provável, o que poderia ter sido e que é tomado como tal. Passível de aceitação, portanto (PESAVENTO, 2004, p.54)

Sendo assim, parto da premissa de que a narrativa apresentada nesta pesquisa possibilita a elaboração de reflexões e explanações sobre o que ocorreu no contexto explorado, porém estes ocorridos podem admitir outras versões se analisados de outra forma ou por outro pesquisador. Dessa forma, não tenho a pretensão de apresentar a história aqui narrada como uma certeza única e absoluta.

A pesquisa apresentada considera aspec- 
tos relativos à feminização do magistério no Colégio Municipal Pelotense, que partem da análise e do estranhamento de diversos documentos escolares, encontrados primordialmente no acervo documental deste estabelecimento.

\section{É importante eviden-} ciar que, de acordo com Yannoulas (2017, p. 283), existem duas conceitualizações que diferenciam e esclarecem a respeito da categoria de feminização das profissões e ocupações, cujos signi-
A pesquisa apresentada considera aspectos relativos à feminização do magistério no Colégio Municipal Pelotense, que partem da análise e do estranhamento de diversos documentos escolares, encontrados primordialmente no acervo documental deste estabelecimento. ficados diferenciam-se de acordo com a metodologia utilizada para análise:

Significado quantitativo (que para efeitos de distinção denominaremos feminilização): refere-se ao aumento.do peso relativo do sexo feminino na composição da mão de obra em um determinado tipo de ocupação;

Significado qualitativo (que denominaremos de feminização propriamente dita): refere-se às transformações em um determinado tipo de ocupação, vinculadas à imagem simbólica do feminino predominante na época ou na cultura especificamente analisadas. Essa imagem pode implicar uma mudança no significado da profissão (YANNOULAS, 201'1, p. 283).
Neste sentido, a ideia de feminização adotada refere-se ao significado qualitativo, pois analisamos a inserção da mulher no magistério do ensino secundário do Pelotense, de acordo com o contexto cultural e as relações de gênero existentes no período estudado. Tendo como ponto de partida a questão de gênero, nossas reflexões ainda abarcam a cultura escolar, definida porJulia (2001, p. 10) como

um conjunto de normas que definem conhecimentos a ensinar e condutas a inculcar, e um conjunto de práticas que permitem a tranșmissão desses conhecimentos e á incorporação desses comportamentos; normas e práticas coordenadas e finalidades que podem variar segundo as épocas (finalidades religiosas, sociopolíticas ou simplesmente de socialização)

Nesta acepção, o autor ainda defende que a cultura escolar "não pode ser estudada sem a análise precisa das relações conflituosas ou pacíficas que 
ela mantém, a cada período de sua história, com o conjunto das culturas que the são contemporâneas: cultura religiosa, cultura política ou cultura popular" (JULIA, 2010, p. 10).

Assim, a cultura escolar permite compreender o contexto escolar do período estudado, a partir da análise da área das disciplinas e sua importância na época, a carga horária dispensada a cada disciplina e o vencimento mensalmente recebido pelos professores, a fim de apontar as diferenças existentes, em relação ao magistério, entre os gêneros neste colégio.

A importância desta pesquisa está em enfatizar e valorizar as ações de mulheres na sociedade, uma vez que, como nos apresenta Louro (1997, p. 17), a "segregação social e política a que as mulheres foram historicamente conduzidas tivera como conseqüência a sua ampla invisibilidade como sujeito - inclusive como sujeito da Ciência.".

Sabe-se que esta contradição entre homens e mulheres, por muito tempo, teve características não de enfrentamento elutas por igualdade, como ul- timamente, mas muito mais de cumplicidade entre os elementos

A relação de patriarcalismo está inserida no contexto de uma determinada época, constituindo, assim, os modos de viver e o tipo de cultura das pessoas que nela viveram. Nesta acepção, para dar sentido à representação exercida pelo homem, concordo com Pesavento novamente quando afirma que

aquele que tem o poder simbólico de dizer e fazer crer sobre o mundo tem o controle da vida social e expressa a supremacia conquistada em uma relação histórica de forças. Implica que esse grupo vai impor a sua maneira de dar a ver o mundo, de estabelecer classificações e divisões, de propor valores e normas, que orientam o gosto e a percepção, que definem limites e autorizam os comportamentos e os papéis sociais (PESAVENTO, 2004, p. 41).

Portanto, não temos pretensão de julgar culpados ou inocentes mas, sim, de apresentar questionamentos pertinentes ao contexto local durante a década de 1940. Nesta perspectiva, analisamos os dados com imparcialidade, sem o erro de cometer anacronismos.

Cabe ainda salientar que, para esta pesquisa, além do acervo do Colégio 
Pelotense, outra instituição de memória vem sendo visitada durante o processo de busca e coleta de documentos que auxiliem a análise das relações sociais na cidade durante o período analisado: a Biblioteca Pública Pelotense.

\section{Trajetórias da pesquisa documental}

O trabalho de mestrado começou com pesquisa no acervo documental do Colégio Pelotense, tendo como foco buscar levantar documentos escolares datados a partir de 1902, ou seja, escrituração escolar existente desde sua fundação. Porém, a pesquisa parte da década de 1940 por ser este o período em que se encontram os primeiros indícios de mulheres no magistério do ensino secundário - o que pudemos constatar especialmente através de diários de classe. Porém, o processo de pesquisa e busca de fontes não se

6 Para este conceito, tem-se sustentação em Saviani (2013, p. 14) no qual este "abrange diferentes tipos de entidades encarregadas de armazénar, preservar e organizar acervos que se constituem como repositório da memória coletiva. São [...] Arquivos públicos e particulares, Museus, Centros Culturais, Centros de Memória e ór.gãos de Preservação do Patrimônio Cultural[...]". ocasionou de forma simples. Como afirmam Lopes e Galvão (2001, p. 79), tanto o problema quanto o tema que o pesquisador se coloca norteiam a escolha das fontes. E continuam:

Trata-se, pois, de identificar no conjunto dos materiais produzidos por uma determinada época, por determinado grupo social, por determinada pessoa - homem ou mulher e segundo a etnia - aqueles que poderão dar sentido à pergunta que inicialmente se propôs; aqueles que, trabalhados, isto é, recortados e reagrupados, poderão servir de base à operação propriamente historiográfica, ou seja, à interpretação e a escrita.

A escolha do tema desta investigação ocorreu de forma inversa ao processo descrito pelas autoras, pois foi ao longo da observação e análise dos diversos documentos encontrados no acervo que surgiram determinadas inquietações e indagações.

Ao depararmos com um ambiente tão rico, como é o caso do Museu do Colégio Municipal Pelotense - criado em 2004, e responsável pela preservação de documentos de cunho escolar e administrativo, fotos e objetos

\footnotetext{
7 Em obra recente, organizada por Amaral (2014), são apresentados os bastidores e relatos de participantes que atuam no acervo do Colégio Municipal Pelotense de diversas formas.
} 
que reportam a história da instituição, peculiar na cidade de Pelotas -, todo documento encontrado despertava o desejo de investigação sobre as condições de sua ordem. Segundo as autoras Samara e Tupy (2010, p. 67),

os documentos que fundamentam os estudos históricos assumem, hoje, as formas mais diversas, abordam diferentes conteúdos e podem ser encontrados em lugares os mais variados. Uma infinidade de registros apresentam-se disponivel atualmente para o trabalho do historiador. Cada vez mais acessíveis, as informações sobre um determinado tema provêm das mais diversas origens: jornais, revistas, livros noticiários de rádio e televisão, filmes, documentários, internet, anedotário, linguagem e oralidade, entre tantas outras, constituem apenas alguns exemplos

No acervo em estudo, constam documentos diversos que abrangem desde a fundação do Colégio Pelotense, em 1902, até os tempos atuais. Estes materiais estão devidamente higienizados e classificados por décadas, enquanto faz-se a digitalização de alguns destes.

Ainda de acordo com Samara e Tupy (2010, p. 118), os documentos "constituem, portanto, uma diversidade de registros que, entendidos em uma dupla perspectiva, possibilitam a realização da crítica histórica, seja sob o ângulo da dimensão material - as formas que assumem - seja sob o da dimensão abstrata - a sua expressão simbólica".

Dentre os vários documentos encontrados no acervo do colégio, destacamos: livros pontos datados a partir de 1914 contendo dia, mês, ano, disciplina, série, nome do professor, conteúdo trabalhado, $n^{\circ}$ da lição professada, $n^{\circ}$ de alunos e observações; diários de classe de diversos professores datados de 1905 a 1961; livros de prestação de contas; atas de exames de promoção, admissão e preparatório, assim como chamadas para os exames, com informações sobre o ano, as disciplinas e a listagem dos alunos que se submeterão aos exames, além dos pontos de conteúdos para os exames orais e escritós, e da nota obtida por cada aluno; livros de chamadas e notas dos alunos; registro de assentamento de alguns professores de 1927, contendo inclusive características físicas dos funcionários, além da descrição de suas atividades profissionais em cada ano; certificados de aprovação nos exames de admissão, promoção 
e preparatórios; além de documentos administrativos como relatórios de inspeção, requerimentos, certificado de equiparação ao Colégio Pedro II em 1925; requerimento para pedido de estadualização do colégio durante a década de 1960, entre outros.

Ao se investigar as fontes como as nossas, documentos es-

E terminamos percebendo que, durante um determinado período, era quase inexistente a presença feminina nos documentos analisados. colares, é importante relevar o que aponta Ragazzini (2001, p. 14):

As fontes permitem encontrar e reconhecer: encontrar materialmente e reconhecer culturalmente a intencionalidade inerente ao seu processo de produção. Para encontrar é necessário procurar e estar disponível ao encontro: não basta olhar, é necessário ver. Para reconhecer é necessário atribuir significado, isto é: ler e indicar os signos e os vestígios como sinais.

No decorrer dessa etapa de "busca" pelas fontes e seleção do material a ser utilizado, tem sido necessário refletir sobre o modo como analisar esses documentos, uma vez que não basta apenas debruçar-se sobre este material, mas há, imprescindivelmente, a necessidade de se problematizar as fontes de pesquisa. Mesmo com todo o encantamento despertado a respeito de tais documentos, havia ainda a necessidade de definir um tema específico para prosseguir a pesquisa de mestrado. Em um dado momento, nos deparamos repetindo por diversas vezes a mesma postura: procurar encontrar vestígios de figuras femininas que tivessem feito parte do colégio, tanto alunas (através da análise da relação de nomes contidos nos Livros de matrícula, chamada e notas e nas Atas e Certificados de exames de admissão, promoção e preparatórios), quanto professoras (através também dos nomes, contidos nos Livros pontos e outros documentos administrativos diversos). E terminamos percebendo que, durante um determinado período, era quase inexistente a presença feminina nos documentos analisados. Assim, pudemos perceber que grande parte das pesquisas estavam relacionadas à inserção de professoras no magistério primário, havendo assim pouco material sobre o ensino secundário, coin- 
cidentemente o ensino inicialmente ofertado pelo colégio. Logo, surgiu o tema que a pesquisa de mestrado se dispõe a investigar, ou seja, a inserção da mulher no magistério do ensino secundário, especificamente no Colégio Municipal Pelotense.

Posteriormente, passamos a realizar a análise dos documentos, com olhar direcionado de pesquisadoras, objetivando agora encontrar os primeiros indícios de registros de professoras ministrando aulas no ensino secundário. Ao longo deste processo, registramos imagens de todo documento que pudesse vir a contribuir com a pesquisa e, posteriormente, elaborei um roteiro de cada dia de investigação no acervo do colégio.

Para o desenvolvimento desta pesquisa, que abrange o período entre 1940 a 1950, priorizamos fontes que permitiram a análise da situação funcional do profissional, a comparação das disciplinas ministradas por professores e professoras, a remuneração destes e, em determinados casos, a carga horária e o índice de aprovação dos alunos naquelas disciplinas.

Desta forma, deu-se início então a um estimulante trabalho de pesquisa que só foi possível, em decorrência do acesso a um acervo escolar, que graças a um esforço colaborativo de integrantes da comunidade escolar, resguarda um ambiente tão rico de fontes, preservadas com tanta satisfação, como é o caso do Museu do Colégio Municipal Pelotense.

Sendo assim, para esta pesquisa ainda em desenvolvimento, propomos realizar uma investigação a respeito de como se desenvolveu o processo de feminização do magistério no ensino secundário do Colégio Municipal Pelotense, partindo da análise crítica de documentos escolares disponíveis no acervo documental do referido colégio, e como é possível notar as relações de poder que se estabeleciam entre professoras e professores tendo, então, a relação de gênero como uma categoria de análise histórica (LOURO, 1987, 1997: MATOS, 1997, 2013).

A categoria de gênero serve para dar sentido à determinada relação de poder e se trata de um elemento constituído de relações sociais fundamentadas nas diferenças percebidas entre os sexos. Bem como destaca Matos (1997, p. 97), 
a categoria [de gênero] reivindica para si um território específico, em face da insuficiência dos corpos teóricos existentes para explicar a persistência da desigualdade entre mulheres e homens... Não se deve esquecer, ainda que as relações de gênero são um elemento constitutivo das relações sociais baseadas nas diferenças hierárquicas que distinguem os sexos, e são portanto, uma forma primária de relações significantes de poder.

Sob esta perspectiva e para apresentar a diferença hierárquica e de prestígio entre professoras e professores do colégio à época, tem-se como indício algumas fontes que permitem a comparação das disciplinas ministradas por professores e professoras, a remuneração destes e em determinados casos, a carga horária dispensada a cada disciplina.

A partir da análise dos documentos contidos

no acervo do colégio, houve a necessidade de investigação no arquivo passivo do Departamento Pessoal, na busca por fichas funcionais e de assentamento das primeiras professoras inseridas no magistério do Colégio Municipal Pelotense:
Em análise do Histórico do Colégio Municipal Pelotense 1902-1952, publicado em 1952, é possível encontrar a relação dos professores que atuaram no colégio até então: dos 100 apresentados, apenas 6 eram mulheres, a saber: Joaquina Ramos, Olindina Nunes Cortelari, Estela Wilkinson (Miss Stelle Wilkinson, de acordo com outros documentos encontrados), Ada Silveira da Costa, Hermelinda Schenkel e Noêmia Bastos Pereira.

Vale destacar que destas seis professoras citadas, apenas a ficha de assentamento referente a Stelle Wi-
Na relação dos professores atuantes em 1952, dos 38 citados no histórico, 7 eram mulheres [...], sendo possivel notar que o corpo docente que compunha o quadro do colégio era de predominância masculina Ikinson foi encontrada dentre a documentação disponível no acervo. Sobre as demais professoras não foram encontrados, nem no acervo tampouco no arquivo passivo do Departamento Pessoal, documentos referente às suas efetivas passagens no colégio.

Ainda neste mesmo histórico, na relação dos professores atuantes em 1952, dos 28 citados no histórico, 7 eram muIheres, sendo elas: Bernardina Nunes 
Ferreira - Profa de Educação Física, Gilda Maciel Alves - Profa de Francês, Helena Iruzun Passos - Profa do Curso Primário, Lucy Sá Lucas - Profa de Trabalhos Manuais, Maria Ester Bitar Real - Profa de Espanhol, Maria Lopes Nunes - Profa de Francês e Maria Soltes - Profa de Canto Orfeônico.

Sendo possível notar que o corpo docente que compunha o quadro do colégio era de predominância masculina, o histórico mencionado sugere problematizações a respeito não só da quantidade de professoras ministrando aulas naquele período, como também sobre as disciplinas lecionadas por elas-que em grande maioria não exigiam efetivamente um grau de formação superior, pois estavam relacionadas, a línguas estrangeiras, que muitas delas possivelmente tenham aprendido para manter um status e padrão exigido pela sociedade pelotense na época.

Outro aspecto para reflexão envolve a representação da mulher neste colégio e até mesmo na Maçonaria, pois mesmo após a municipalização do Colégio Pelotense, não era raro que seus professores fossem membros da Ordem Maçonaria.
A análise das fontes está sendo feita segundo a história cultural abordada por Pesavento (2004, p. 42), em que "o historiador lida com uma temporalidade escoada, com o não-visto, o não-vivido, que só se torna possível acessar através de registros e sinais do passado que chegam até ele". Entre os documentos pesquisados, foram encontradas as fichas funcionais de seis professoras e a ficha de assentamento de apenas uma. Em seguida, para uma análise mais consistente, foi elaborada uma tabela, apresentada a seguir, a partir da ficha funcional e de assentamento destas professoras, a fim de estabelecer comparações e problematizações sobre as mesmas.

Conforme a Tabela 1, é possível notar alguns aspectos como, por exemplo, a inexistência de üma formação superior específica às disciplinas das quais foram admitidas para leciónar.

Outro aspecto importante é o fato de a maioria destas professoras serem admitidas para ministrar aulas de língua estrangeira, o que permite inferir que estas mulheres, de alguma forma, faziam parte da sociedade pelotense mais abonada, pois para as meninas da época, o mais importante eram os 
conhecimentos de prendas domésticas, literatura e linguagens, pois estes seriam os conhecimentos úteis, necessários e suficientes para acompanhar seus respectivos maridos perante a sociedade (LOURO, 1987; TAMBARA, 1995; NEVES, AMARAL \& TAMBARA, 2012).

Tabela 1 - Dados contidos nas fichas funcionais e de assentamento das professoras (1940-1950)

\begin{tabular}{|c|c|c|c|c|c|c|c|}
\hline Nome & Disciplina & $\begin{array}{l}\text { Dados sobre } \\
\text { ingresso }\end{array}$ & $\begin{array}{l}\text { Nacimento } \\
\text { idade de } \\
\text { ingresso }\end{array}$ & Naturalidade & Estado civil & Filhos & $\begin{array}{c}\text { Formação / Ano de } \\
\text { obtenção do Registro } \\
\text { Professor }\end{array}$ \\
\hline Stelle Wilkinson & Inglês & $1 \% / 4 / 1925$ & $\begin{array}{c}1893 \\
32 \text { anos }\end{array}$ & $\begin{array}{l}\text { Londres- } \\
\text { Inglaterra }\end{array}$ & & & \\
\hline $\begin{array}{l}\text { Bernardina } \\
\text { Nunes } \\
\text { Ferreira }\end{array}$ & Ed. Física & $\begin{array}{c}\text { Adm.: } 1928 \text { à } \\
1939 \\
\text { Readm.: } \\
1 / 1 / 1942\end{array}$ & $\begin{array}{c}1904 \\
24-38 \text { anos }\end{array}$ & Pelotas-RS & Casada & 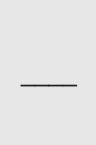 & $\begin{array}{c}\text { Complementar, Ed. } \\
\text { Física. } \\
\text { Registro: } 1943\end{array}$ \\
\hline $\begin{array}{c}\text { Maria Ester Bitar } \\
\text { Real }\end{array}$ & Espanhol & $\begin{array}{l}\text { Nomeada } \\
\text { interina: } \\
1 / 4 / 1943 \\
\text { Efetivada: } \\
1 / 1 / 1962\end{array}$ & $\begin{array}{c}1916 \\
27 \text { anos }\end{array}$ & $\begin{array}{l}\text { Melo-Uruguai } \\
\text { (Brasileira } \\
\text { naturalizada) }\end{array}$ & Casada & 1941 & $\begin{array}{c}\text { Escola normal do } \\
\text { Uruguai. } \\
\text { Registro: } 1949\end{array}$ \\
\hline $\begin{array}{l}\text { Maria Soltes da } \\
\text { Silveira }\end{array}$ & $\begin{array}{l}\text { Canto } \\
\text { Orfênico }\end{array}$ & $\begin{array}{c}\text { Adm.: } \\
\text { 16/10/1945 } \\
\text { Nomeada } \\
\text { interina: } \\
\text { 10/3/1952 } \\
\text { Readm.: } \\
\text { 16/10/1956 } \\
\text { Efetivada: } \\
\text { 1/1/1962 }\end{array}$ & $\begin{array}{c}1920 \\
25 \text { anos }\end{array}$ & Pelotas-RS & Casada & $\begin{array}{l}1949 \\
1959\end{array}$ & $\begin{array}{l}\text { Cursos: Piano, canto, } \\
\text { harmonia, Superior } \\
\text { em Canto orfênico, } \\
\text { tenoria e solfejo. } \\
\text { Registro: } 1951\end{array}$ \\
\hline $\begin{array}{l}\text { Gilda Maciel } \\
\text { Alves }\end{array}$ & Francês & $\begin{array}{l}\text { Adm.: } \\
\text { 2/3/1948 } \\
\text { Nomeada } \\
\text { interina: } \\
\text { 19/5/1951 }\end{array}$ & $\begin{array}{c}1908 \\
43 \text { anos }\end{array}$ & $\begin{array}{c}\text { Porto Alegre } \\
\text { - RS }\end{array}$ & Viúva & $\begin{array}{l}1935 \\
1937 \\
1938 \\
1943\end{array}$ & $\begin{array}{l}\text { Instrução secundária. } \\
\text { Registro: } 1948\end{array}$ \\
\hline Lucy Sá Lucas & $\begin{array}{c}\text { Trab. Manuais } \\
\text { e Econ. } \\
\text { Doméstica }\end{array}$ & $\begin{array}{c}\text { Adm.: } \\
\text { 1/8/1949 } \\
\text { Nomeada } \\
\text { interina: } \\
\text { 19/5/1951 }\end{array}$ & $\begin{array}{c}1909 \\
40 \text { anos }\end{array}$ & Pelotas-RS & Solteira & 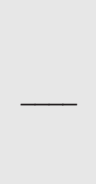 & $\begin{array}{c}\text { Escola de belas artes, } \\
\text { Esp. em Trabalhos } \\
\text { manuais } \\
\text { Registro: } 1947\end{array}$ \\
\hline $\begin{array}{c}\text { Maria Luiza Lopes } \\
\text { Nunes }\end{array}$ & Francês & $\begin{array}{l}\text { Adm.: } \\
\text { 15/3/1951, } \\
\text { no curso de } \\
\text { admissão }\end{array}$ & $\begin{array}{c}1906 \\
45 \text { anos }\end{array}$ & Pelotas-RS & $\begin{array}{l}\text { Casada/ } \\
\text { Viúva }\end{array}$ & 1929 & $\begin{array}{c}\text { Cinasial. } \\
\text { Registro: } 1956\end{array}$ \\
\hline
\end{tabular}

Fonte: Elaborado pelas autoras. 


\section{Considerações finais}

Ainda que a pesquisa ainda esteja em andamento, é possível notar, principalmente, a riqueza de conteúdos e histórias que envolvem os documentos escolares e a importância destes para a História da Educação, possibilitando ao pesquisador o contato direto com documentos e dados que podem representar a realidade vivenciada no período em que se pretende analisar, além de apresentar também os bastidores da instituição e as relações de poder que permeiam seus interiores, trazendo aspectos que também compõem sua história.

Certamente, ainda há muitos outros documentos e diários de classe a serem analisados. Porém, pode-se notar, até o momento, que mesmo com todo o debate da época e o discurso de inserção da mulher no ensino primário, as relações de gênero envolvidas no ensino secundário neste período ainda privilegiavam a classe masculina, ao menos nesta instituição. Outra questão levantada a partir da documentação está relacionada aos motivos pelos quais uma instituição que discursava sobre uma educação laica e mista demora um tempo considerável para àderir à inserção da mulher em seu quadro de funcionários. Pelo exposto, de acordo com os documentos encontrados até o momento, é necessário notar que, mesmo o ensino primário da época estando em cargo das mulheres, o ensino secundário ainda era reservado prioritariamente à classe masculina.

\section{Referências}

AMARAL, C. L. O Cymnasio Pelotense e a Maçonaria: uma face da história da ed ucação em Pelotas. 2.ed. Pelotas: Seiva, 2005. (org.). Museu do Colégio Municipal Pelotense. Pelotas: EDUCAT, 2014.

CERTEAU, M. A escrita da história. Tradução de Maria de Lourdes Menezes. 2. ed. Rio de Janeiro: Forense Universitária, 2000.

HISTÓRICO DO COLÉGIO MUNICIPAL PELOTENSE (1902-1952). Pelotas: Of. Gráficas da Liv. Do Clobo S.A, 1952. 
JULIA, D. A cultura escolar como objeto histórico. Tradução de Gizele de Souza. Revista Brasileira de História da Educação, Maringá, v. 1, n. 1, p. 9-43, jan./jun. 2001. Disponível em: <http://www.rbhe.sbhe. org.br/index.php/rbhe/article/view/273/281>. Acesso em: 4 set. 2015.

LOPES, E. M. T.; CALVÃO, A. M. O. História da educação: o que você precisa saber sobre. Rio de Janeiro: DP\&A, 2001.

LOURO, G. L. Prendas e Antiprendas: uma escola de mulheres. Porto Alegre: UFRGS, 1987.

Gênero, sexualidade e educação: uma perspectiva pós-estruturalista. Petrópolis: Vozes, 1997.

MATOS, M. I. S. Outras histórias: as mulheres e estudos dos gêneros - percursos e possibilidades. In: SAMARA, E. M. et ali (Orgs.). Cênero em Debate: trajetória e perspectiva da historiografia contemporânea. São Paulo: EDUC, 1997. p. 83-174.

História das mulheres e das relações de gênero: campo historiográfico, trajetórias e perspectivas. Mandrágora, São Paulo, v. 19, n. 19, p. 5-15, dez. 2013. Instituto Metodista de Ensino Superior. http://dx.doi.org/10.15603/2176-0985/mandragora.v19n19p5-15

NEVES, H.A.; AMARAL, G. L.; TAMBARA, E.A.C.A oferta do ensino primário e secundário investigada por meio da propaganda impressa (1875-1910). Revista Diálogo Educacional, Curitiba, v. 12. n. 36, p. 459-483, maio/ago. 2012. Disponivel em: <http://www2.pucpr.br/reol/index.php/ dialogo?dd99=pdf\&dd1=6096>. Acesso em: 4 set. 2015.

NUNES, D. Pesquisa historiográfica: desafios e caminhos. Revista de Teoria da História, Coiânia, v. 2, n. 5, p. 15-25, jun. 2011. Disponivel em: <https://www.revistas.ufg.br/teoria/article/downlo$\mathrm{ad} / 28959 / 16131>$. Acesso em: 4 set. 2015.

PESAVENTO, S. J. História \& História Cultural. Belo Horizonte: Autêntica, 2004.

RACAZZINI, D. Para quem e o que testemunham as fontes da história da educação? Educarem revista, Curitiba, n. 18, p. 13-27, jul./dez. 2001. Disponível em: <http://www.scielo.br/pdf/er/n18/n18a03. pdf>. Acesso em: 2 jun. 2016.

SAMARA, E. M.; TUPY, I. S. S. T. História \& Documento e metodologia.de pesquisa. 2. ed. Belo Horizonte: Autêntica, 2010.

TAMBARA, E. Positivismoe educação. Pelotas: UFPel, $1995^{\circ}$

VECHIA, A. O ensino secundário no século XIX: instruindo as elites. In: STEPHANOU, M.; BASTOS, M. H. C. História e memória da educação no Brasil. 3. ed. Petrópolis: Vozes, 2010. v. 2, p. 78-89.

YANNOULAS, S. C. Feminização ò feminilização? Apontamentos em torno de uma categoria. Temporalis, Brasília, v. 11, n. 22, p. 271-292, jul./dez. 2011. 